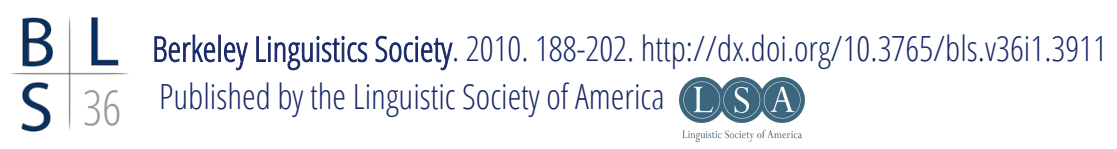

\title{
Negative Concord in Western Armenian
}

\author{
HRAYR KHANJIAN \\ Massachusetts Institute of Technology
}

\section{Introduction}

This paper examines a unique phenomena of negative concord found in Western Armenian (WA). When two negative morphemes appear together in the same clause, there are two possible interpretations that result cross-linguistically. Either each negative morpheme contributes a negation to the semantics, known as double negation (DN) or the two morphemes surface as one instance of negation, know as negative concord (NC). Standard English and Dutch are examples of languages that exhibit DN, where each instance of a negation adds to the semantics as seen in (1).

(1) John didn't do nothing. $=$ John did + Neg do + Neg.thing "John did actually do something."

Greek, Russian and Armenian are examples of NC languages as exemplified by the Greek example in (2), where a negative argument TIPOTA and sentential negation Dhen together in the same clause result in just one negative meaning.

(2) Dhen ipa TIPOTA not said.1sg n-thing "I didn't say anything."

[Greek] (from Giannakidou, 2000:458)

Western Armenian differs from most other negative concord languages in that the verbal negative marker is completely optional in the presence of any n-word. ${ }^{1}$ Secondly, a double negation meaning is possible with two verbal negative markers in the same clause. I propose that negative meaning in WA comes from verbal negation. When verbal negation is absent a covert negative operator gives the negative interpretation following the approach used by Zeijlstra (2004).

The main focus of the data collected is on interpretation. I examined what meaning speakers of WA understand when hearing certain sentences. The main

\footnotetext{
${ }^{1}$ Terminology after Laka (1990), referring to negative indefinites like English no one, nothing.
} 
distinction I was examining was whether a sentence had a negative interpretation or a positive one, the latter suggesting that two negative morphemes had canceled each other out giving a double negation reading. Therefore sentences in this paper have not necessarily been extracted from everyday colloquial WA speech. All examples in this paper are given in IPA. All voiceless stops and affricates are aspirated in WA. For convenience I have omitted all aspiration diacritics.

\section{Western Armenian Negation}

Western Armenian (WA) is one of the major dialects of Armenian, spoken all over the world, mostly in non-post-soviet countries. Armenian is historically an IndoEuropean language which has been significantly influenced by the presence of the Altaic language Ottoman Turkish for the past millenia. It is a highly agglutinating, predominantly head final, highly scrambling language. The WA sub-dialect that is examined in this paper is that of the Lebanese/Syrian Western Armenian variety spoken in America. Other sub-dialects might have slightly different properties and patterns with respect to negation, which I will not be examining in this paper.

Negation on the verb is marked with the suffix $t f+\mathrm{i} / \partial$ depending on the following verb and rate of speech. An example is seen in (3). In slow speech consonant initial verbs take $t \int i$-. In quicker speech, the stressless $i$ reduces to a ə giving the form $t \int \partial-$. For vowel initial verbs the negative marker is always of the form $t \int-$.

(3) Aram-ə dun t $\int i$-kənats

Aram-DEF home NEG-went.3S

"Aram didn't go home"

The WA lexical item corresponding to English "no" is votf. This free morpheme can be uttered as the answer to a polar question (4).

(4) Aram-ə dun kənats? > vot

Aram-DEF home went.3S? $>$ no

"Did Aram go home?" > "no"

There is no morphosyntactic difference, with respect to case or marking on any arguments or the verb, between a sentence with an n-word and a sentence with an indefinite. This is demonstrated by the following pair where the first, (5) is a positive and the second, (6) contains the corresponding n-word.

(5) pan-mə gerav thing-INDEF ate. $3 \mathrm{~S}$

"He/She ate something"
(6) vot -meg-pan gerav no-one-thing ate.3S "He/She ate nothing"

Semantically the n-word in (6) seems like a fully negative word such as English nothing. However we will see that this is not the case, namely that a covert operator provides the negative meaning. To note, sentential negation is not required in (6). 
The n-words in WA are formed with this "no" morpheme as seen from the table below. There are two sets of n-words that are used in Western Armenian. The first set (A) does not contain the morpheme meg "one." The second set (B) on the other hand is very parallel to a Turkish agglutinating structure where the "no" morpheme is added to infinitive strings such as the negative word hitf-bir-fej "not-one-thing" which is identical to vot $\int$-meg-pan "no-one-thing". 2

\begin{tabular}{|c|c|c|c|}
\hline (Indefinites) & $\begin{array}{l}\text { meg-ə } \\
\text { des-mə } \\
\text { pan-mə }\end{array}$ & $\begin{array}{l}\text { one-DEF } \\
\text { place-INDEF } \\
\text { thing-INDEF }\end{array}$ & $\begin{array}{l}\text { "someone" } \\
\text { "somewhere } \\
\text { "something" }\end{array}$ \\
\hline (Set A n-words) & $\begin{array}{l}\text { vot } \int-\text { vok } \\
\text { vot } \int-\text { des } \\
\text { vot } \int-\text { int } \int\end{array}$ & $\begin{array}{l}\text { no-individual } \\
\text { no-place } \\
\text { no-what }\end{array}$ & $\begin{array}{l}\text { "no one" } \\
\text { "nowhere" } \\
\text { "nothing" }\end{array}$ \\
\hline (Set B n-words) & $\begin{array}{l}\text { vot } \int-m e g-\partial \\
\text { vot } \int-m e g-d e s \\
\text { vot } \int-m e g-p a n\end{array}$ & $\begin{array}{l}\text { no-one-DEF } \\
\text { no-one-place } \\
\text { no-one-thing }\end{array}$ & $\begin{array}{l}\text { "no one" } \\
\text { "nowhere" } \\
\text { "nothing" }\end{array}$ \\
\hline
\end{tabular}

The same negative sentence can be obtained with a verbal negative marker, without any n-words. Negation scopes above either subject, (7), or object, (8) and is therefore interpreted over the indefinites.

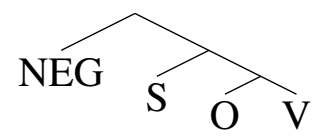

(7) meg-ə Aram-i-n t ti-desav

one-DEF Aram-DAT-DEF NEG-saw.3S

"No one saw Aram"

$\mathrm{NEG}>\exists$

(8) Aram-ə pan-mə $t \int i$-gerav

Aram-DEF thing-INDEF NEG-ate.3S

"Aram didn't eat anything" NEG $>\exists$

Lastly, n-words can appear in a number of positions: subjects (9), objects (6) or locatives (10):

(9) votf-meg-ə dun kənats

no-one-DEF home went.3S

"No one went home"

2 There is inter-speaker variation as to which form set (A) or (B) of the n-word is used. 
(10) Aram-ə kirk-ə vot $\int-m e g-d е в$ tərav

Aram-DEF book-DEF no-one-place put.3S

"Aram didn't put the book anywhere"

$\mathrm{N}$-words can be used as fragmentary answers to polar questions. A negative interpretation results as seen in (11). The negative polarity item corresponding to anyone cannot occur in this context in WA as opposed to n-words, which is a property seen cross-linguistically (Watanabe 2004).

$$
\begin{aligned}
& \text { 30воv-i-n ov nerga je-r? > vot } \text {-meg-ə, *vojeve-meg-ə } \\
& \text { meeting-DAT-DEF who present is-PAST.3S > no-one-DEF, *any-one-DEF } \\
& \text { "Who was present at the meeting?" > No one", *Anyone }
\end{aligned}
$$

To note, in Western Armenian the pre-verbal string usually receives some form of sentential stress. However if the verb is negated the sentential stress shifts to the negative prefix. Also a weaker stress is places on n-words if any are present. ${ }^{3}$

Besides n-words and verbal negative markers, negation can also be expressed with negative adpositions like without (Penka 2007:24). In WA the equivalent lexical item is the negative preposition arants, as seen by the example in (12).

[arants (pan-mə) ude-l-u] dun katsi

[without (thing-INDEF) eat-INF-DAT] home went.1S

"I went home, without eating (anything)"

The negative preposition in (12) can be replaced by either the verbal negative marker $t \int(i)$ - or an n-word resulting in a similar statement as seen in (13) and (14). ${ }^{4}$

$$
\begin{aligned}
& {\left[(\text { pan-mə }) \quad t \int \text {-ude-l-ov/ } t \int i \text {-ger-adz }\right] \text { dun katsi }} \\
& {[(\text { thing-INDEF }) \text { NEG-eat-INF-INST/ NEG-eat-PERF }] \text { home went.1S }} \\
& \text { "I went home, not eating/having not eaten" }
\end{aligned}
$$

$$
\begin{aligned}
& \text { [votf-meg-pan ude-l-ov] dun katsi } \\
& \text { [no-one-thing eat-INF-INST] home went.1S }
\end{aligned}
$$$$
\text { "I went home, eating nothing" }
$$

The three adjunct phrases in the three preceding examples all express one negation. In $\S 1.2$ I will show how these phrases give rise to double negation meanings when another negative morpheme is present in the matrix clause.

\footnotetext{
${ }^{3}$ Some speakers might interpret the same string of words differently given different stress patterns.

${ }^{4}$ There is a semantic temporal difference between the presence of the dative case on the infinitival verb and the instrumental case on the infinitival verb. With the dative, seen with the use of the verbal preposition, the action has been completed when the second verb is in motion. This applies to the perfect in (13) as well. With the instrumental case seen with verbal negation or an n-word, both verbal actions are taking place at the same time. I will not discuss this semantic difference since it is not relevant to this paper. What is relevant is that a negative meaning can be expressed with either a negative preposition, an n-word or a verbal marker in these adjunct clauses.
} 


\section{Negative Concord in Western Armenian}

\subsection{Negative Concord in Western Armenian}

Negative Concord in Western Armenian is clearly seen when an n-word co-occurs with a sentential negation marker as seen in (15). As stated before sentential negation is optional in WA. ${ }^{5}$ The important fact to note is that when present, sentential negation does not contribute a second negation to the semantics, therefore not resulting in a DN meaning.

$$
\begin{aligned}
& \text { votf-int } \int(t f i) \text {-desa } \\
& \text { no-what (NEG)-see.PAST.1S } \\
& \text { "I didn't see anything" (NC) } \\
& \text { *“I didn't see nothing" (DN) }
\end{aligned}
$$

Two negative objects as seen in (16) also do not result in a DN interpretation, as they would in English. As seen from (17), three n-words will again yield one negation to the semantics. As before the negative marker on the main verb is optional.

vot $\int-m e g-\partial$ vot $\int-m e g-p a n(t f i)$-gerav

no-one-DEF no-one-thing (NEG)-ate.3S

"No one ate anything" (NC)

*"No one (did not) eat nothing" (DN)

$$
\begin{aligned}
& \text { vot } \int-\text { meg-ə vot } \int-m e g-\mathrm{u}-\mathrm{n} \quad \text { vot } \int-\mathrm{meg}-\mathrm{pan}(\mathrm{t} f \mathrm{i}) \text {-dəvav } \\
& \text { no-one-DEF no-one-DAT-DEF no-one-thing (NEG)-gave.3S } \\
& \text { "No one gave anything to anyone" (NC) } \\
& \text { *"No one (didn't) give (no)thing to (no) one" (DN) }
\end{aligned}
$$

Finally NC is seen in negative clauses like in "without" clauses where the without word and an n-word or verbal negation result in only one negative meaning as seen from the following example. As long as the n-word, verbal negation and/or the negative prepositional complementizer are in the same clause, only one negative meaning arises.

$$
\begin{aligned}
& \text { [arants vot } \left.\int \text {-meg-pan }\left(t \int i\right) \text {-kəne-l-u }\right] \text { dun katsi } \\
& \text { [without no-one-thing (NEG)-buy-INF-DAT] home went.1S } \\
& \text { "I went home, without buying anything" }
\end{aligned}
$$

There are two types of NC-phenomena discussed in the literature, negative doubling and negative spread Watanabe (2004:559-560). Like in Italian and West Flemish, both of these NC types are found in WA. Negative doubling is when the sentential negation marker cooccurs with a NC item as seen in (15). Whereas negative spread involves two or more negative concord items as seen in (16).

\footnotetext{
${ }^{5}$ This seems to not be the case for Eastern Armenian.
} 
Hrayr Khanjian

\subsection{Double Negation in Western Armenian}

There are instances of double negation, where two negative morphemes in a sentence each contribute a negation to the semantics. The first case, in which the two negative morphemes are separated by a clause boundary, is seen in almost all negative concord languages (Giannakidou 2000:492). In the following example (19) an n-word is in the matrix clause with a verbal negation in the embedded clause. Since there are two negative morphemes separated by a clause boundary, we get a DN reading.

(19) vot $\int-m e g-ə$ gə-gardze [vor Aram-ə dun t $\int i$-kənats]

no-one-DEF IMPF-think.3S [that Aram-DEF home NEG-went.3S]

"No one thinks that Aram didn't go home"

The same is true if we have verbal negation in the matrix clause, and an n-word in the embedded clause as seen in (20). In fact any negation in the matrix with any negation in the embedded $\mathrm{CP}$ results in double negation.

(20) Aram-ə t ti-gardze-r [vor vot -meg-ə dun kənats]

Aram-DEF NEG.BE.3S-think-IMPF [that no-one-DEF home went.3S]

"Aram doesn't think that no one went home"

Another example of across the clause double negation is with "without" clauses introduced earlier. In (21), we see a "without" clause and a verbal negation on the main matrix verb. The result is a double negation interpretation. ${ }^{6}$

(21) [arants kəne-l-u] dun t $\int i$-katsi

[without buy-INF-DAT] home NEG-went.1S

"Without buying [anything] I didn't go home"

There are clauses that are parallel to the "without" clauses as presented before. The following two sentences show that once again with two negative morphemes across such a boundary, we get double negation. In (22) the nominalized verb is carrying the verbal negation morpheme. With the n-word in the matrix clause, this verbal negative marker produces a DN meaning.

(22) $\left[\left(\right.\right.$ pan-mə) $\quad t \int i$-kəne-l-ov $] \quad$ vot $\int-m e g-d е в ~ k a t s i$

[(thing-INDEF) NEG-buy-INF-INST] no-one-place went.1S

"Without buying anything I went nowhere"

\footnotetext{
${ }^{6}$ It must be noted here that some speakers were unable to interpret these sentences. This is not a confound and does not conflict with any of the DN judgments since it shows that there is something more going on than just a NC interpretation.
} 


\section{Negative Concord in Western Armenian}

The indefinite object of the nominalized verb in (22) can be replaced with an n-word giving the same double negation reading with the presence of a matrix negative morpheme as seen in (23).

[vot $\int-m e g-p a n$ kəne-l-ov] vot f-meg-des katsi

[no-one-thing buy-INF-INST] no-one-place went.1S

"Without buying anything I went nowhere"7

The second case of DN arises with multiple verbal negative markers in the same clause. The verbal negative marker can appear on either the finite matrix verb or on a modal like "will" or "must". (24) and (25) show that any two verbal negative markers result in a DN meaning.

(24) menk heradesil bedk-tfe $t$ ti-tide-nk

1PL.NOM television must-NEG NEG-watch-1PL

"We must not not watch TV" = "We must watch TV"

(25) $t$ fo-bidi $t$-ude-m

NEG-will NEG-eat-1S

"I will not not eat" = "I will eat"

To summarize, in Western Armenian two n-words or an n-word and verbal negation result in a negative concord reading if in the same clause. However when two verbal negative markers come together a double negation reading arises. Also across clauses we get DN as expected from n-words in $\mathrm{NC}$ languages. As a reminder the verbal negative marker is optional with any n-word in WA.

\section{$2 \quad$ Negative Concord Cross-Linguistically}

In this section I present how multiple negative morphemes behave in other languages. The three main relevant types of negative morphemes found cross-linguistically are 1) bound verbal negation affixes or clitics like the Turkish - $m A$ - and Czech $n e$, 2) free [non-bound] negative adverbs like the West Flemish nie and English not and 3) n-words, which contain morphological negative strings and can be the arguments of the verb like English nothing, nowhere, Italian nessuno and Czech nikomu.

There are two possible interpretations when two negative morphemes appear together in the same clause as introduced above. If each negative morpheme contributes a semantic negation the result is a double negation interpretation exemplified in languages like Standard English, Dutch and German (26).

(26) Dieses Jahr hat kein Student nicht bestanden.

this year has n-DET student NEG passed.

"This year, no student didn't pass"

="This year, every student passed"

[German] (from Penka 2007:19)

\footnotetext{
${ }^{7}$ In this sentence the nominalized verb can also be in the perfect as seen before in (13).
} 
If the two negative items together contribute just one instance of semantic negation we get a negative concord reading as demonstrated above for WA. Other negative concord languages include Greek, Italian, Portuguese and Russian (27).

(27) Nichego ne rabotaet

n-thing NEG works

"Nothing works"

[Russian] (from Zeijlstra, 2004:3)

Giannakidou $(2000,2002)$ splits NC languages into strict and non-strict negative concord languages. In strict NC languages, a negative marker is obligatory with both subject and object n-words and DN meanings are not possible, such as in Russian and Greek (28) and (29).

(28) KANENAS dhen irthe

n-body NEG came

"Nobody came"

[Greek] (from Zeijlstra, 2004:126)

(29) Dhen ipa TIPOTA

not said.1sg n-thing

"I didn't say anything"

[Greek] (from Giannakidou, 2000:458)

However in non-strict NC languages like Italian and Portuguese, n-words only yield NC interpretations in the object position, where sentential negation is also required (30). Verbal negation is disallowed with the presence of subject $n$-words (31). In non-strict languages, a possible DN reading arises if the verbal negation marker appears with an emphasized subject n-word (Zeijlstra 2004:129).

O Rui não viu ningém

Rui NEG looked at.n-body

"Rui didn't look at anybody"

[Portuguese] (from Zeijlstra, 2004:130)

(31) Ninguém (*não) veio

N-body NEG came

"Nobody came"

[Portuguese] (from Zeijlstra, 2004:130)

The difference between strict and non-strict NC languages can be restated as an asymmetry in non-strict NC languages with respect to n-words in subject versus object position, which is not found in strict NC languages where both subject and object n-words are treated the same. Following this generalization, Western Armenian is a strict NC language since subjects (32) and objects (33) are treated the same. The main difference between the strict languages sketched above and WA is that the sentential negation marker is optional in WA.

vot $\int$-meg-ə dza $\left(t \int i\right)$-gerav

no-one-DEF food (NEG)-ate.3S

"No one ate food" 


\section{Negative Concord in Western Armenian}

(33) Aram-ə vot $\int-m e g-p a n(t f i)$-desav

Aram-DEF no-one-thing (NEG)-saw.3S

"Aram saw nothing"

There is a small group of languages like WA where a sentential negative marker is optional with n-words like Bavarian, Quebecois, West Flemish (34) and a variety of Catalan (Haegeman 1995, Zeijlstra 2004, Haegeman and Lohndal 2008). These are strict NC languages (Zeijlstra 2004).

\section{...da Valère niemand (nie) ken}

...that Valère n-body (NEG) knows

“...that Valère doesn't know anybody” [W. Flemish] (From Zeijlstra, 2008:2)

Besides the optionality of the negative marker, in these optional NC languages, DN meanings can arise due to scrambling of a negative adverb. For example, in West Flemish a DN interpretation arises when the negative adverb nie "not" precedes the n-word as seen in (35), compared to (34). ${ }^{8}$

...da Valère nie niemand (en)-kent

...that Valère not nobody NEG-know

“...that Valère doesn't know nobody” [W. Flemish] (From H \& L, 2008:11)

Western Armenian lacks such a negative free morpheme adverb. Therefore we cannot test if double negation readings arise through scrambling. However DN readings are possible in the same clause in WA with multiple verbal negative markers as discussed in the previous section:

$$
\begin{aligned}
& t \text { J-bidi } t \int \text {-ude-m } \\
& \text { NEG-will NEG-eat-1S } \\
& \text { "I will not not eat" = "I will eat" }
\end{aligned}
$$

Summarizing the different types of languages presented in this section, negative concord languages are split into strict and non-strict languages. In non-strict languages object n-words require verbal negation marking, where as in strict languages both the object and the subject n-words require a verbal negation marker. Language like West Flemish, Standard Dutch and Western Armenian do not require a sentential negative marker with n-words. In Standard Dutch if a verbal negation appears with an n-word, a double negation reading results, unlike in West Flemish and Western Armenian where a negative concord reading arises. Finally both Standard Dutch and West Flemish have negative adverbs. These adverbs can scramble in West Flemish to get double negation readings. This scrambling is not possible in Western Armenian, but double negation readings arise with two verbal markers.

${ }^{8}$ For extensive discussion of the minimal pair (34) vs. (35) see Haegeman and Lohndal (2008). 
Hrayr Khanjian

\section{$3 \quad$ Accounting for Negative Concord}

There is a very large pool of literature discussing many languages with n-words, negative concord and at times NPIs. There are a few different approaches as to how to account for the distribution of NC cross-lingusitically. Some of the recent literature that includes discussion and analysis of n-words are: Ladusaw (1992), Giannakidou (2000), Herburger (2001), de Swart and Sag (2002), Watanabe (2004), Zeijlstra (2004, 2008) and Penka (2007) and references within each of them. All of these approaches fail to take into account a certain aspect of the data available in the literature. In this paper I only look at how Zeijlstra's $(2004,2008)$ analysis would account for the Western Armenian data. His system seems to be able to straightforwardly apply to and account for the greatest diversity of languages.

\subsection{Syntactic Agree, Zeijlstra (2004)}

Zeijlstra $(2004,2008)$ proposes a feature checking explanation to account for the different types of negative concord. He extends the syntactic tool of syntactic Agree to negation, as had been done with pro-drop subject/objects and verbal agreement marking (Zeijstra 2008:21). Negative morphemes carry either interpretable [iNEG] or uninterpretable [uNEG] features. All [uNEG] features need to be checked by an [iNEG] feature and deleted before interpretation. Two conditions must hold for this checking to occur. First, the [iNEG] feature must be in a c-commanding relation to the [uNEG] feature. Second, both [iNEG] and [uNEG] need to be in the same domain/phrase. Another assumption about the syntactic theory used is that of multiple Agree where one [iNEG] can multiply Agree with many [uNEG]s. ${ }^{9}$ The clause boundedness of negative concord, which was discussed above, reflects the locality conditions on syntactic agreement.

In negative concord languages all n-words carry [uNEG] features. The difference between strict and non-strict languages is borne out from the feature on verbal negation. In strict NC languages verbal negation carries [uNEG] and in non-strict $\mathrm{NC}$ languages the verbal negation marker carries an [iNEG]. Therefore Czech necarries [uNEG], while Italian non carries [iNEG]. In double negation languages like Standard English all n-words and negative morphemes carry [iNEG]. Each instance of [iNEG] contributes one negative value to the semantics. All [uNEG] features need to be checked, therefore all n-words in strict NC languages and preverbal nwords in non-strict NC languages will require a licensor that is not found in the covert phonological sentence. In these cases a covert negative operator $(\mathrm{Op} \neg)$, carrying an [iNEG] feature, is posited in Spec, NegP that contributes the negation. This operator is only inserted as a last resort (Zeijlstra 2004:246). For more details, examples and applications consult Zeijlstra (2004, 2008) and Penka (2007).

${ }^{9}$ Haegeman \& Lohndal (2008) deem multiple Agree unnecessary, claiming simple Agree suffices. 


\section{Negative Concord in Western Armenian}

\subsection{Agreement Applied to Western Armenian}

In this section I show how non-strict negative features, namely [iNEG] features for verbal negation markers, need to be posited for WA which seems to be a more strictlike negative concord language. Western Armenian subject and object n-words are treated the same as mentioned before. Following Zeijlstra (2004), since Western Armenian is considered to be a strict NC language, n-words and verbal negation carry [uNEG] features, like Czech or West Flemish.

However I argue that WA verbal negation carries an [iNEG] feature like nonstrict languages since every instance of a verbal negation, $t \int i-$, contributes a negation to the semantics as is seen by examples like (37). ${ }^{10}$

$$
\begin{aligned}
& t \int \partial \text {-bidi } t \int \text {-ude-m } \\
& \text { NEG-will NEG-eat-1S } \\
& \text { "I will not not eat" = "I will eat" }
\end{aligned}
$$

Before demonstrating how the checking works in Western Armenian I will show that the verbal negative marker must carry an [iNEG] feature.

\subsubsection{Why [iNEG] for Verbal Negation in Western Armenian?}

There are two alternatives to assuming that the verbal negative marker carries an [iNEG] feature, which I will show fail to account for the Western Armenian facts. The first is that the verbal negation carries a [uNEG] feature just like all strict negative concord languages. Coming back to the example seen in (37), this would mean that the two verbal negative markers would each trigger a negative covert operator to be inserted as depicted in (38). This can be done if each negative morpheme is in a different clause, as was seen across $\mathrm{CP}$ boundaries.

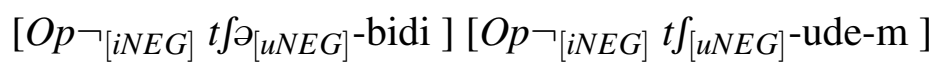

The issue with this assumption arises when n-words are added to the sentence in (37), as in (39).

vot $\int$-meg-pan $t \int$-bidi $t \int$-ude-m

no-one-thing NEG-will NEG-eat-1S

"I will not not eat anything" = "I will eat anything"

Which phrase is this n-word a part of, the phrase that contains "will" or the one containing the finite verb "eat"? With the assumption that there are two phrases, as in (38), the answer to this question is not straightforward.

\footnotetext{
${ }^{10}$ Penka (2007:81 fn 49) points out, three or more NIs do not have more than two negation readings.
} 
The following examples (40) and (41) both yield negative concord readings with the same resulting meanings. ${ }^{11}$

vot $\int$-meg-pan $t \int \partial$-bidi ude-m

no-one-thing NEG-will eat-1S

"I will eat nothing"

vot $\int$-meg-pan bidi $t$-ude-m

no-one-thing will NEG-eat-1S

"I will eat nothing"

The example in (40) suggests that the n-word and the negative marker on the modal "will" are in the same clause since only one negative reading results. The same is true for (41), where the n-word and the verbal negative marker on the finite verb "eat" must be in the same clause. At this point there are two possible options as to where the n-word is located. The first option is that will and eat are in two different clauses. The n-word in (40) is in the same clause as will and the n-word in (41) is in the clause with the eat. I disregard this option since it seems arbitrary and convenient for the same n-word to be in two different clauses depending on what other negative items exist or do not exist in the rest of the sentence. The second option is to claim that all three elements, the n-word argument, the verbal negation on the modal "will" and the verbal negation on the finite verb "eat" are in the same clause. However if we conclude that all three of these morphemes are in the same clause, and assume that the verbal negative morphemes carry [uNEG] features, then the only possible reading for (39) is a negative concord reading with one interpretable negation resulting from one c-commanding negative covert operator as shown in (42), which is the incorrect reading. Either way at this juncture it can not be the case that all verbal negative markers carry [uNEG] features.

$$
*\left[O p \neg[i N E G] \text { vot } \int_{[u N E G]^{-m e g-p a n} t \int \partial[u N E G]} \text {-bidi } t \int_{[u N E G]}\right]^{- \text {ude-m }]}
$$

Another logical or theoretical possibility to the verbal negative markers carrying [iNEG] features is that some carry [uNEG] features and some carry [iNEG] features. This option has a few downfalls, morphophonological and syntactic. For space limitations I will skip the details of how it fails to capture all the negation facts of WA.

From the arguments given above I conclude that all verbal negative markers, namely all allomorphs of the form $t \int+\mathrm{i} / 2$ carry [iNEG] features. As with all other negative concord languages the n-words of Western Armenian carry [uNEG] features which need to be checked before interpretation. In the following subsection I will show how the checking of these negative features gives the correct surface interpretations of the Western Armenian data presented above.

${ }^{11}$ Other NC languages like Russian do get DN readings with two verbal negative markers. However, n-words require a verbal negative marker on the finite verb "will" and cannot appear with just a negative marker on the non-finite verb. This is not the case for WA where both is possible. 


\section{Negative Concord in Western Armenian}

\subsubsection{Checking Demonstrated in Western Armenian}

Now I will go through the different combinations of n-word and verbal negation and show how a syntactic agreement approach accounts for the negative concord facts presented above. I use the simple example sentence in (43) to demonstrate the checking. To reiterate, all vot $\int$ morphemes carry an uninterpretable negative feature, while the verbal negation $t f i$ - morphemes carry interpretable features.

(vot $\left.\int\right)$-meg-ə kirk (t $\left.f i\right)$-gartats

no-one-DEF book NEG-read.3S

"No one read any book"

In the following trees I place the NegP projection in a dominance relation with $v \mathrm{P}$ which contains the subject and object arguments as well as the verb being negated. Zeijlstra (2004:165-181) discusses in detail the location of NegP with respect to other phrasal projections, the negative elements that can project $\mathrm{NegP}$ and the cross-linguistic availability of NegPs. Another point to make is that in all the trees I assume the subject is inside the $v \mathrm{P}$ when checking of the negative features occurs. To account for the linear order of a subject initial sentence, I assume following Zeijlstra (2004) that the subject scrambles out of $v \mathrm{P}$, a property of highly scrambling languages like West Flemish.

When an n-word and verbal negation are present in a sentence the verbal negation's [iNEG] feature checks the n-word's [uNEG] feature as seen in the configuration in (44). Checking can occur since the [iNEG] feature is in a c-command relation with the [uNEG] feature and they are both in the same clause. All the examples discussed here have subject $n$-words for convenience. The same checking applies to object n-words in WA.

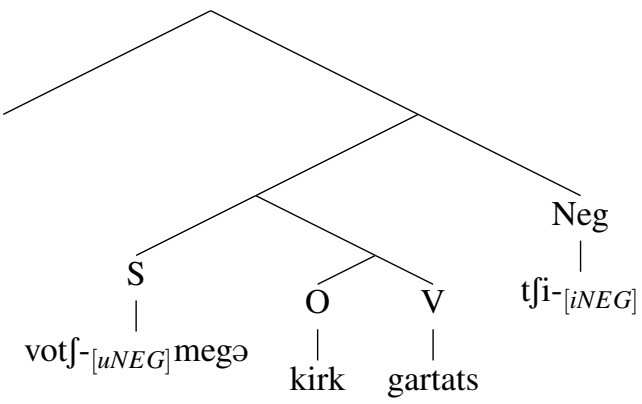

However, as discussed before, in Western Armenian the n-words can occur without the presence of a verbal negative marker. In these cases, like the tree in (45), the [uNEG] feature of the n-word is left unchecked. Therefore a Op $\neg$ is inserted carrying [iNEG], which checks off the n-word's [uNEG]. This covert negative operator is inserted in the same projection as the verbal negative marker, as in (44). 
(45)

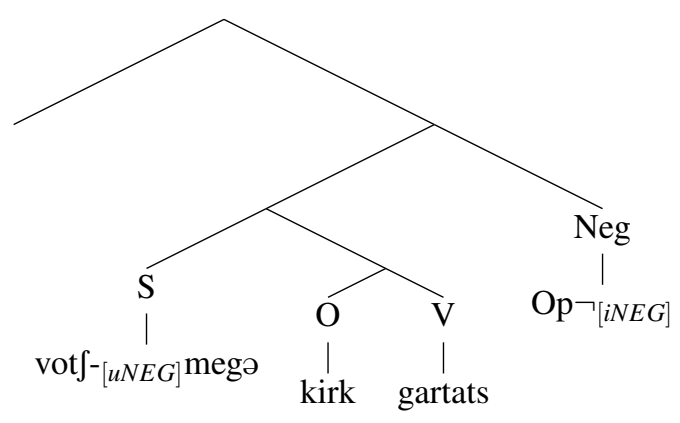

When two negative markers appear in a clause, namely in complex verbal constructions discussed above, a double negation reading arises. An example is repeated in (46). Each verbal negative marker carries an [iNEG] feature as seen in (47). The lower verbal negative marker's [iNEG] will check the [uNEG] feature of the n-word in the subject position.

vot $\int$-meg-ə kirk $t$ fə-bidi $t \int i$-garta

no-one-DEF book NEG-will NEG-read.3S

"Nobody will not read any book"

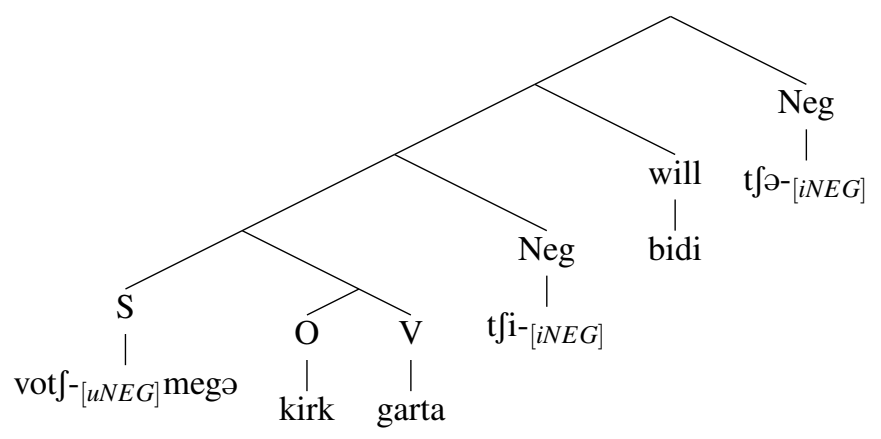

The other case of double negation found in the Western Armenian data is acrossclause negation. These are cases where there are two negative elements, either nwords or verbal negation, where each is in separate clauses. This is clearly demonstrated across a CP boundary, as seen by the following example. In (48) there is an n-word in the matrix clause and another in the embedded clause. The nwords' [uNEG] features cannot be checked off by the same [iNEG] feature since the [uNEG] features are not in the same clause. Therefore two covert negative operators are inserted as seen in (49), resulting in double negation.

votf-meg-ə gə-gardze [vor Aram-ə votf-meg-pan kənets] no-one-DEF IMPF-think.3S [that Aram-DEF no-one-thing bought.3S]

"No one thinks that Aram didn't buy anything"

$$
O p \neg[i N E G] \operatorname{vot} \int_{[u N E G]^{-m e g-\partial ~ \ldots . ~[v o r ~} O p \neg[i N E G]} \ldots \text { vot } \int_{\left.[u N E G]^{-m e g-p a n ~} \ldots\right]}
$$




\section{Negative Concord in Western Armenian}

\section{Conclusion}

Presenting the interaction of negative elements in WA, I expanded the typology of possible NC languages. I showed how WA NC can be explained using the syntactic agreement approach following Zeijlstra $(2004,2008)$. However a modification was needed where a strict NC language required non-strict $\mathrm{NC}$ negation features.

\section{References}

Giannakidou, Anastasia. 2000. Negative...concord? NLLT 18(3):457-523.

Haegeman, Liliane. 1995. The syntax of negation. Cambridge Studies in Linguistics 75, Cambridge University Press.

Haegeman, Liliane \& Terje Lohndal. 2008. Negative Concord and (Multiple) Agree: A Case Study of West Flemish. Unpublished Manuscript.

Herburger, Elena. 2001. The negative concord puzzle revisited. NLS 9(3):289-333.

Ladusaw, William A. 1992. Expressing negation. In C. Barker and D. Dowty, eds., In Proceedings of SALT II, 237-259, Cornell, NY: Cornell Linguistics Circle.

Laka, Itziar. 1990. Negation in Syntax: on the Nature of Functional Categories and Their Projections. Ph.D. thesis, Massachusetts Institute of Technology.

Penka, Doris. 2007. Negative Indefinites. Ph.D. thesis, University of Tübingen.

de Swart, Henriette \& Ivan Sag. 2002. Negative Concord in Romance. Linguistics and Philosophy 25:373-417.

Watanabe, Akira. 2004. The Genesis of Negative Concord: Syntax and Morphology of Negative Doubling. Linguistic Inquiry 35(4):559-612.

Zeijlstra, Hedde. 2004. Sentential Negation and Negative Concord. Ph.D. thesis, University of Amsterdam.

Zeijlstra, Hedde. 2008. Negative Concord in Syntactic Agreement. Ms. University of Amsterdam.

Hrayr Khanjian

Massachusetts Institute of Technology

Department of Linguistics and Philosophy, 32D-808

77 Massachusetts Avenue

Cambridge, MA 02139

hkhanjian@gmail.com 